\title{
$O$ transtorno do espectro autista e seu impacto no desenvolvimento infantil: uma
}

\section{revisão integrativa}

\author{
Autism spectrum disorder and its impact on child development: an integrative review \\ Trastorno del espectro autista y su impacto en el desarrollo infantil: una revisión integradora
}

Recebido: 02/03/2021 | Revisado: 08/03/2021 | Aceito: 19/03/2021 | Publicado: 25/03/2021

Hellen Pereira Melo

ORCID: https://orcid.org/0000-0003-1813-7577 Faculdade de Ciências Humanas, Exatas e da Saúde do Piauí, Brasil Instituto de Educação Superior do Vale do Parnaíba, Brasil E-mail: hellenmelo1996@gmail.com

Fabbio Ronnyel Rodrigues Baldoino

ORCID: https://orcid.org/0000-0003-4393-6039 Faculdade de Ciências Humanas, Exatas e da Saúde do Piauí, Brasil Instituto de Educação Superior do Vale do Parnaíba, Brasil E-mail: fabbiobald@gmail.com

Helane Pereira Melo

ORCID: https://orcid.org/0000-0003-2783-9562 Centro Universitário UNINOVAFAPI, Brasil Faculdade de Saúde Ciências Humanas e Tecnologia do Piauí, Brasil E-mail: helanemelo3@gmail.com

Kássio Roberto de Barros Alves

ORCID: https://orcid.org/0000-0001-8259-5607 Centro Universitário UNINOVAFAPI, Brasil Faculdade de Saúde Ciências Humanas e Tecnologia do Piauí, Brasil E-mail: kassioalvess@hotmail.com

Lorenna Kellyne Rodrigues Baldoino ORCID: https://orcid.org/0000-0001-6839-5430 Centro Universitário Facid Wyden, Brasil E-mail: lorennabaldoino@hotmail.com

Tays Bruna Leal Cunha

ORCID: https://orcid.org/0000-0003-2382-1509 Centro Universitário UNINOVAFAPI, Brasil Faculdade de Saúde Ciências Humanas e Tecnologia do Piauí, Brasil E-mail: taysblc@hotmail.com

\begin{abstract}
Resumo
Objetivo: O objetivo desta pesquisa é analisar, na literatura científica, o impacto do Transtorno do Espectro Autista (TEA) no desenvolvimento infantil, identificar quais aspectos do desenvolvimento infantil são mais afetados pelo Autismo e analisar o processo de aprendizagem da criança autista. Metodologia: Trata-se de uma pesquisa bibliográfica desenvolvida por meio do método Revisão Integrativa. Resultados: Os resultados apontam que os aspectos mais afetados no desenvolvimento infantil são o atraso no Desenvolvimento Neuropsicomotor relacionados à motricidade global, equilíbrio e linguagem/organização temporal, alterações essas que ocorrem de forma não linear e podem repercutir no processo de aprendizagem. Sobre o processo de aprendizagem da criança autista, a literatura aponta que esse processo deve ser realizado através de metodologias pedagógicas diferenciadas para que essa criança crie autonomia e progresso em sua aprendizagem. Conclusão: Conclui-se que o acompanhamento diário e especializado da criança com TEA revela o quanto se faz necessário um profissional de apoio que esteja preparado, que busque alternativas criativas e lúdicas que adaptadas e individualizada, facilitando assim a aprendizagem de crianças com TEA.
\end{abstract}

Palavras-chave: Transtorno do espectro autista; Desenvolvimento; Infância.

\section{Abstract}

Objective: The objective of this research is to analyze, in the scientific literature, the impact of Autistic Spectrum Disorder (ASD) on child development, to identify which aspects of child development are most affected by Autism and to analyze the learning process of the autistic child. Methodology: This is a bibliographic research developed using the Integrative Review method. Results: The results show that the most affected aspects in child development are the delay in Neuropsychomotor Development related to global motor skills, balance and language / temporal organization, changes that occur in a non-linear way and can have an impact on the learning process. Regarding the learning process of the autistic child, the literature points out that this process must be carried out through different 
pedagogical methodologies so that this child creates autonomy and progress in their learning. Conclusion: It is concluded that the daily and specialized monitoring of children with ASD reveals how much it is necessary for a support professional who is prepared, who seeks creative and playful alternatives that are adapted and individualized, thus facilitating the learning of children with ASD.

Keywords: Autism spectrum disorder; Development; Childhood.

\section{Resumen}

Objetivo: El objetivo de esta investigación es analizar, en la literatura científica, el impacto del Trastorno del Espectro Autista (TEA) en el desarrollo infantil, identificar qué aspectos del desarrollo infantil son los más afectados por el Autismo y analizar el proceso de aprendizaje del niño autista. Metodología: Se trata de una investigación bibliográfica desarrollada mediante el método de Revisión Integrativa. Resultados: Los resultados muestran que los aspectos más afectados en el desarrollo infantil son el retraso en el Desarrollo Neuropsicomotor relacionado con la motricidad global, el equilibrio y la organización del lenguaje/temporal, cambios que ocurren de forma no lineal y pueden tener impacto en el proceso de aprendizaje. En cuanto al proceso de aprendizaje del niño autista, la literatura señala que este proceso debe realizarse a través de diferentes metodologías pedagógicas para que este niño genere autonomía y avance en su aprendizaje. Conclusión: Se concluye que el seguimiento diario y especializado de los niños con TEA revela cuánto es necesario un profesional de apoyo que esté preparado, que busque alternativas creativas y lúdicas, adaptadas e individualizadas, facilitando así el aprendizaje de los niños con TEA.

Palabras clave: Trastorno del espectro autista; Desarrollo; Infancia.

\section{Introdução}

Para que o desenvolvimento de indivíduos autistas aconteça, vai depender do contexto social, da interação com as pessoas para que se possam proporcionar meios de superação das características autistas. A partir dessa interação o aluno autista consegue ser incluído na sala de aula, e desse modo, diminuir os estereótipos. Esse convívio com outros alunos neurotípicos fornece novas e diversas experiências afetivas tanto com as pessoas (o professor e os alunos) quanto com a aprendizagem (Cunha, 2014).

Nesse contexto, ressaltamos a relevância de aliar aspectos interacionistas e afetivos, tanto nas relações sociais e pedagógicas como também no atendimento terapêutico também está exposta no trabalho de Cunha (2014), que faz uma enumeração das atividades que devem ser trabalhadas com o aluno que possui autismo e aponta que tais práticas devem possuir caráter terapêutico, social, pedagógico e afetivo. Os objetivos são:

\footnotetext{
"Terapêutico - superar comportamentos inadequados; social - proporcionar atividades em sala de aula comum, desenvolvendo a interação entre o aluno autista e os outros alunos; pedagógico - ajudar na conscientização de sua história para aprimorar sua individualidade como aprendiz; e criar o vínculo com o processo de aprendizagem, com o professor e com o espaço escolar, pela mediação do interesse e do desejo, em atividades lúdicas e educativas" (Cunha, 2014, p. 54).
}

Nota assim, que o ensino de convenções sociais é de extrema importância para o desenvolvimento da criança autista. Apesar de não aprenderem com facilidade é necessário tentar fazer a criança internalizar a regra. Faz-se necessário a criação de um vínculo entre a criança e seus pares mediado pelo professor, e também criar a vontade de aprender os conteúdos acadêmicos e a convivência social. Quem convive ou trabalha com alunos que tem autismo deve sempre lutar pelo seu desenvolvimento geral, pois, é válido “[...] tentar desenvolver atitudes, crenças e estratégias positivas para enfrentar a situação" (Williams \& Wright, 2008, p. 30).

No tocante as questões normativas e legais, identificamos que desde no ano de 2008, foi aprovada a Política Nacional de Educação Especial na perspectiva da Educação Inclusiva que determinou que todos os alunos com necessidades educacionais especiais fossem matriculados em turmas de ensino regular e atendimentos de forma complementar em Sala de Atendimento Educacional Especializado - AEE. Essa perspectiva paradigmática inclusiva, supera a, visão integracionista que 
apregoava que "[...] uma criança com deficiência só permanecia em uma sala regular se acompanhasse o ritmo da turma" (Santos \& Melo, 2018).

Apesar de diversos profissionais desistirem dos alunos especiais, houve aqueles que superaram as expectativas. Nesse sentido, não basta aceitar a criança na sala de aula e não fornecer um trabalho educacional de qualidade. Para realizar um trabalho com alunos autistas Cunha (2016) aponta que a linguagem do professor deve ser a mais clara e simples possível, o professor necessita, antes de tudo, aprender a entender qual o sentido que o aluno dá às suas palavras. "Precisamos descobrir como penetrar em seu mundo imagético e simbólico" para trabalhar com alunos com extrema dificuldade comunicativa "[...] onde há déficit de comunicação". Uma das metodologias está em o educador fazer utilização cartões com imagens ou figuras para incentivar a linguagem e a comunicação do aluno (Cunha, 2016, p. 38).

$\mathrm{O}$ autismo é um distúrbio que se origina na primeira infância e tem efeitos extremamente desfavoráveis em vários aspectos do desenvolvimento social, familiar e escolar. O primeiro impacto do diagnostico vem severamente para a família, que, por muitas vezes, não sabem como reagir (Sasson; Nowlin \& Pinkham, 2012).

O prejuízo na área social pode ser descrito por condições e situações incapacitantes que limitam ou impedem o autista de interagir. A dificuldade de manifestações de interações sociais acarreta, dentre outros prejuízos, limitação na área da linguagem e do pensamento. Os prejuízos advindos da limitação na área da linguagem são descritos como aqueles que mais angustiam os pais e os profissionais que trabalham com o autismo.

Apesar de ser um transtorno relativamente novo, já existem mudanças nos contextos e diagnósticos, e criações de instrumentos confiáveis que possibilitam diagnósticos válidos que contribuem em progressos de pesquisas.

Atualmente, a sociedade passou a ver a criança com Transtorno do Espectro Autista (TEA) com outros olhos. Hoje com novas características, não tendo como ponto característico a delimitação do próprio portador. O indivíduo invariavelmente tem dificuldades de desenvolvimento social, neste momento torna-se importante a ajuda da sociedade para tornar mais fácil a inclusão do autista.

Trata-se um trabalho de cunho qualitativo por meio de uma pesquisa bibliográfica que utilizará o método da revisão integrativa e que objetiva refletir com base na literatura científica o impacto do Transtorno do Espectro Autista - TEA no desenvolvimento infantil, identificar quais aspectos do desenvolvimento infantil são mais afetados pelo Autismo e analisar o processo de aprendizagem da criança autista.

\section{Metodologia}

Trata-se de uma pesquisa bibliográfica qualitativa desenvolvida por meio do método Revisão Integrativa.

A revisão integrativa é um método de pesquisa que tem como finalidade sintetizar resultados obtidos em pesquisas sobre um tema ou questão, de maneira sistemática, ordenada e abrangente. É denominada integrativa porque fornece informações mais amplas sobre um assunto/problema, constituindo, assim, um corpo de conhecimento.

Deste modo, o revisor/pesquisador pode elaborar uma revisão integrativa com diferentes finalidades, podendo ser direcionada para a definição de conceitos, revisão de teorias ou análise metodológica dos estudos incluídos de um tópico particular (Marconi \& Lakatos, 2014).

Para a construção da revisão integrativa é preciso percorrer seis etapas distintas, sendo elas a identificação do tema e seleção da hipótese ou questão de pesquisa; estabelecimento de critérios para inclusão e exclusão de estudos/amostragem ou busca na literatura; definição das informações a serem extraídas dos estudos selecionados/ categorização dos estudos; avaliação dos estudos incluídos; interpretação dos resultados; e apresentação da revisão/síntese do conhecimento (Mendes; Silva \& Galvão, 2008). 
As fontes de busca foram o banco de dados da Biblioteca Virtual de Saúde (BVS) por meio da Literatura Latino Americana e do Caribe em Ciências da Saúde (LILACS) e Medical Literature Analysis and Retrieval System Online (MEDLINE).

Além destas bases também foi utilizada a Scientifc Eletronic Library Online (SciELO) por meio dos seguintes descritores: "Transtorno do espectro autista", "Desenvolvimento", "Infância".

Esses descritores foram usados de forma combinada nas bases de dados indicadas._As pesquisas selecionadas para compor o estudo obedeceram aos seguintes critérios de inclusão: ter sido publicada entre 2015 a 2019 e retratou os impactos do transtorno do espectro autista no desenvolvimento infantil.

Foram excluídos estudos que não retratavam a temática em pauta, as duplicações e pesquisas de revisão.

Os dados coletados foram analisados de maneira interpretativa e integrada para melhor responder aos objetivos propostos.

Finalmente os dados foram interpretados, sintetizados e conclusões foram formuladas originadas dos vários estudos incluídos na revisão integrativa (Mendes; Silveira \& Galvão, 2008).

Os resultados foram avaliados e apresentados em uma tabela que mostra quais são os impactos ocasionados pelo transtorno do espectro autista no desenvolvimento infantil, as intervenções e estratégias desenvolvidas para minimizar esses impactos.

Também foram construídas tabelas para caracterizar a autoria, ano do estudo, periódico, amostra do estudo e metodologia adotada, bem como os principais resultados das pesquisas selecionadas para compor este estudo.

Posteriormente, os resultados dos estudos analisados foram discutidos e conclusões foram elaboradas a partir dos estudos elencados.

\section{Resultados}

Após a busca nos bancos de dados eletrônicos, optou-se por descrever a aplicação dos critérios de inclusão e exclusão por meio de representação gráfica construída com a utilização do Microsoft Office Word 2019. 
Figura 1. Representação gráfica do processo de seleção dos estudos e artigos encontrados segundos os critérios de inclusão e exclusão.

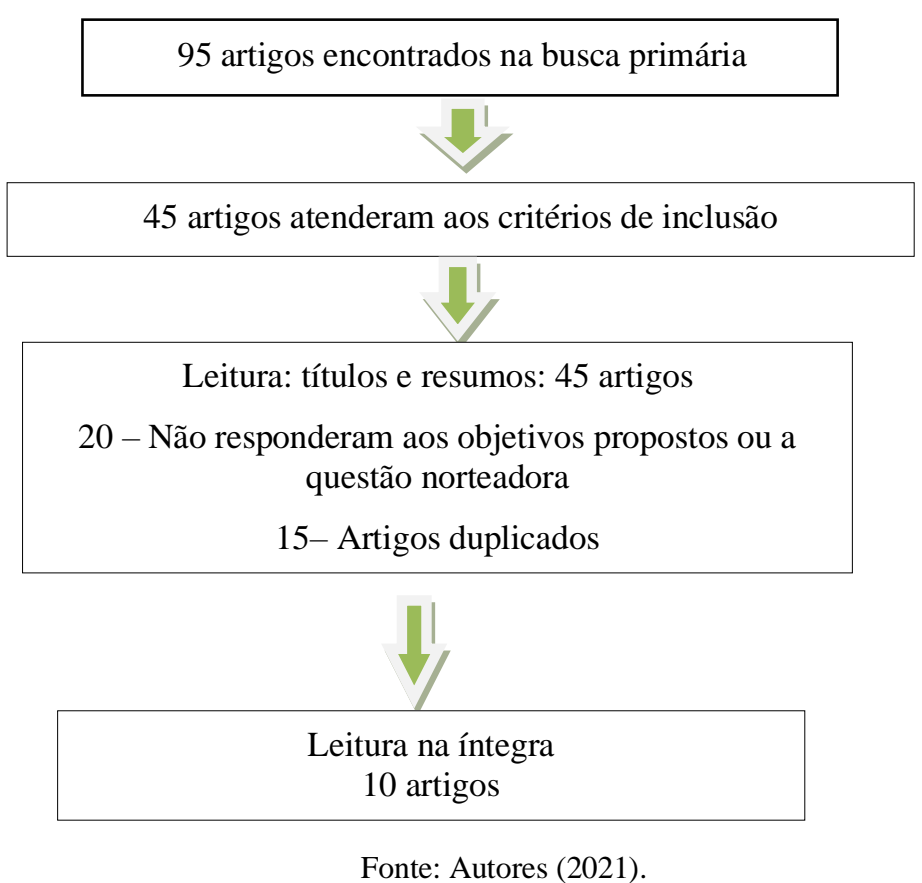

Observaram-se noventa e cinco (95) ocorrências (estudos e/ou artigos) durante a busca primária, após o cruzamento dos descritores: "Transtorno do espectro autista", "Desenvolvimento", "Infância", e estão demonstrados abaixo de acordo com a base de dados pesquisada.

Quadro 1. Distribuição dos artigos encontrados na busca primária segundo as Bases de Dados pesquisadas.

\begin{tabular}{ccc}
\hline SCIELO & MEDLINE & LILACS \\
\hline 55 artigos & 30 artigos & 10 artigos \\
\hline
\end{tabular}

Fonte: Autores (2021).

De acordo como descrito na Figura 1, após a aplicação dos critérios de exclusão, foram selecionados 10 artigos para a elaboração desta revisão integrativa.

Na Tabela 1 estão descritas as características dos 10 artigos e/ou estudos selecionados para a elaboração da revisão e estão apresentadas as características como título do artigo, autor, tipo de estudo, ano e amostra.

Tabela 1. Características dos artigos selecionados para a revisão nas bases de dados SCIELO, MEDLINE e LILACS no período de 2015 a 2019.

\begin{tabular}{|c|c|c|c|c|}
\hline Ordem & Título do estudo & Autor e Ano & $\begin{array}{c}\text { Desenho } \\
\text { metodológico }\end{array}$ & Amostra \\
\hline 01 & $\begin{array}{c}\text { Vivências Escolares e } \\
\text { Transtorno do } \\
\text { Espectro Autista: o } \\
\text { que Dizem as } \\
\text { Crianças? }\end{array}$ & Ramos et al., 2019. & Pesquisa qualitativa & $\begin{array}{c}42 \text { crianças, na faixa } \\
\text { etária de } 4-5 \text { anos, de } \\
\text { duas instituições de } \\
\text { Educação Infantil da } \\
\text { cidade de João Pessoa- } \\
\text { Paraíba }\end{array}$ \\
\hline
\end{tabular}


Research, Society and Development, v. 10, n. 3, e52610312620, 2021

(CC BY 4.0) | ISSN 2525-3409 | DOI: http://dx.doi.org/10.33448/rsd-v10i3.12620

\begin{tabular}{|c|c|c|c|c|}
\hline 02 & $\begin{array}{l}\text { Perfil Psicomotor de } \\
\text { Crianças com } \\
\text { Transtorno do } \\
\text { Espectro Autista em } \\
\text { Maceió/AL }\end{array}$ & Anjos et al., 2017. & Pesquisa quantitativa & $\begin{array}{l}30 \text { crianças com idades } \\
\text { entre } 2 \text { e } 11 \text { anos, de } \\
\text { ambos os gêneros, com } \\
\text { diagnóstico de TEA leve. }\end{array}$ \\
\hline 03 & $\begin{array}{c}\text { Caracterização } \\
\text { psicomotora de } \\
\text { criança autista pela } \\
\text { escala de } \\
\text { desenvolvimento } \\
\text { motor. }\end{array}$ & $\begin{array}{l}\text { Santos e Melo, } \\
2018 .\end{array}$ & Estudo de Caso & $\begin{array}{c}01 \text { menino de } 10 \text { anos } \\
\text { com diagnóstico de } \\
\text { Autismo. }\end{array}$ \\
\hline 04 & $\begin{array}{l}\text { As contribuições da } \\
\text { equoterapia para o } \\
\text { desenvolvimento } \\
\text { psicomotor da criança } \\
\text { com transtorno do } \\
\text { espectro autista. }\end{array}$ & $\begin{array}{l}\text { Cruz e Pottker, } \\
2017\end{array}$ & Pesquisa qualitativa & $\begin{array}{c}10 \text { crianças com } \\
\text { diagnóstico de autismo. }\end{array}$ \\
\hline 05 & $\begin{array}{l}\text { Rastreio de alterações } \\
\text { cognitivas em } \\
\text { crianças com TEA: } \\
\text { estudo piloto }\end{array}$ & $\begin{array}{l}\text { Tomazoli et al., } \\
2017 .\end{array}$ & Pesquisa qualitativa & $\begin{array}{c}14 \text { indivíduos, dos } \\
\text { gêneros feminino e } \\
\text { masculino, com faixa } \\
\text { etária entre } 48 \text { ( } 2 \text { anos) e } \\
71 \text { meses ( } 5 \text { anos e } 11 \\
\text { meses) }\end{array}$ \\
\hline 06 & $\begin{array}{c}\text { Protocolo de } \\
\text { Avaliação de Crianças } \\
\text { com Autismo: } \\
\text { Evidências de } \\
\text { Validade de Critério }\end{array}$ & $\begin{array}{l}\text { Marques e Bosa, } \\
2015 .\end{array}$ & Pesquisa quantitativa & $\begin{array}{c}\text { Participaram } 30 \text { crianças, } \\
\text { entre dois e quatro anos, } \\
\text { divididas em três grupos } \\
\text { (Desenvolvimento } \\
\text { Típico, Síndrome de } \\
\text { Down e Autismo) }\end{array}$ \\
\hline 07 & $\begin{array}{c}\text { Experiência dos } \\
\text { familiares no convívio } \\
\text { de crianças com } \\
\text { transtorno do espectro } \\
\text { autista (TEA) }\end{array}$ & $\begin{array}{l}\text { Hofzmann et al., } \\
2019 .\end{array}$ & Pesquisa qualitativa. & $\begin{array}{c}\text { Familiares de } 13 \text { crianças } \\
\text { autistas }\end{array}$ \\
\hline 08 & $\begin{array}{c}\text { Experiências de } \\
\text { professores com o } \\
\text { autismo: impacto no } \\
\text { diagnóstico precoce e } \\
\text { na inclusão escolar }\end{array}$ & Couto et al., 2019. & Pesquisa qualitativa & $\begin{array}{l}\text { Dez (10) professores de } \\
\text { dez Centros Municipais } \\
\text { de Educação Infantil de } \\
\text { Foz do Iguaçu, Paraná, } \\
\text { Brasil. }\end{array}$ \\
\hline
\end{tabular}


Research, Society and Development, v. 10, n. 3, e52610312620, 2021

(CC BY 4.0) | ISSN 2525-3409 | DOI: http://dx.doi.org/10.33448/rsd-v10i3.12620

\begin{tabular}{|c|c|c|c|c|}
\hline 09 & $\begin{array}{c}\text { Atendimento } \\
\text { multidisciplinar para a } \\
\text { educação especial e } \\
\text { inclusiva de uma } \\
\text { criança com } \\
\text { transtorno do espectro } \\
\text { autista: um estudo de } \\
\text { caso }\end{array}$ & Melo et al. 2019. & Estudo de caso & $\begin{array}{c}\text { Uma (01) criança com } \\
\text { TEA. }\end{array}$ \\
\hline 10 & $\begin{array}{l}\text { Inclusão e autismo: } \\
\text { relato de caso sobre o } \\
\text { trabalho com uma } \\
\text { criança na educação } \\
\text { infantil }\end{array}$ & $\begin{array}{c}\text { Teixeira e Ganda, } \\
2019 .\end{array}$ & Estudo de caso & $\begin{array}{c}\text { Uma (01) criança com } \\
\text { diagnóstico de TEA }\end{array}$ \\
\hline
\end{tabular}

Fonte: Autores (2021).

Tabela 2. Intervenções, resultados, instrumentos utilizados e conclusões dos artigos selecionados para a revisão nas bases de dados SCIELO, MEDLINE e LILACS no período de 2015 a 2019.

\begin{tabular}{|c|c|c|c|c|}
\hline Artigo & Intervenções realizadas & Instrumentos & Resultados & Conclusões \\
\hline 01 & $\begin{array}{c}\text { Foram aplicadas } \\
\text { entrevistas } \\
\text { semiestruturadas com as } \\
\text { crianças com } \\
\text { desenvolvimento típico, } \\
\text { que foram transcritas e } \\
\text { analisadas a partir da } \\
\text { técnica de análise de } \\
\text { conteúdo de Bardin. }\end{array}$ & $\begin{array}{c}\text { Questionário } \\
\text { semiestruturado }\end{array}$ & $\begin{array}{c}\text { Como resultados, as crianças } \\
\text { mencionaram adjetivos positivos ao } \\
\text { descreverem sua creche, professora } \\
\text { e colegas, tanto no início quanto no } \\
\text { final do ano letivo. Também foi } \\
\text { comum as crianças descreverem a } \\
\text { creche em termos das atividades } \\
\text { que realizavam em sua rotina, e as } \\
\text { pessoas, em relação aos seus } \\
\text { comportamentos. }\end{array}$ & $\begin{array}{l}\text { Discute-se, por fim, a } \\
\text { importância de estudar a } \\
\text { inclusão escolar a partir da } \\
\text { perspectiva das crianças. }\end{array}$ \\
\hline 02 & $\begin{array}{l}\text { Aplicou-se, inicialmente, } \\
\text { um instrumento de coleta } \\
\text { de dados com os } \\
\text { responsáveis pela criança. } \\
\text { Posteriormente foi } \\
\text { realizada avaliação da } \\
\text { criança em relação à } \\
\text { escala de } \\
\text { desenvolvimento motor de } \\
\text { Rosa Neto. }\end{array}$ & $\begin{array}{l}\text { Escala de } \\
\text { desenvolvimento } \\
\text { motor de Rosa } \\
\text { Neto }\end{array}$ & $\begin{array}{l}\text { Verificou-se que as crianças com } \\
\text { TEA avaliadas obtiveram menor } \\
\text { idade motora para os elementos } \\
\text { psicomotores de organização } \\
\text { temporal e esquema corporal e } \\
\text { maior para motricidade global e } \\
\text { equilíbrio. O escore do quociente } \\
\text { motor geral das crianças com } \\
\text { Transtorno do Espectro Autista } \\
\text { encontrado foi de } 77,3 \pm 16,9, \\
\text { sendo as mesmas classificadas em } \\
\text { um nível inferior, na escala de } \\
\text { desenvolvimento motor de Rosa } \\
\text { Neto. }\end{array}$ & $\begin{array}{l}\text { O estudo concluiu que deve } \\
\text { utilizar-se dos princípios da } \\
\text { psicomotricidade como } \\
\text { fundamento sensório-perceptivo- } \\
\text { motor durante o tratamento das } \\
\text { crianças com Transtorno do } \\
\text { Espectro Autista, visto que as } \\
\text { mesmas apresentam alterações } \\
\text { nos aspectos psicomotores. }\end{array}$ \\
\hline 03 & $\begin{array}{l}\text { A avaliação foi realizada } \\
\text { individualmente em } \\
\text { ambiente tranquilo. Essa } \\
\text { avaliação consiste na } \\
\text { análise de equilíbrio, } \\
\text { esquema corporal, } \\
\text { organização temporal, } \\
\text { lateralidade e motricidade } \\
\text { fina e global realizadas de } \\
\text { forma lúdica para facilitar } \\
\text { a participação da criança. }\end{array}$ & $\begin{array}{c}\text { Escala de } \\
\text { desenvolvimento } \\
\text { motor (EDM) de } \\
\text { Rosa Neto }\end{array}$ & $\begin{array}{l}\text { Para a criança autista avaliada, de } \\
\text { forma geral a idade motora foi } \\
\text { negativa de } 2 \text { anos, ou seja, } \\
\text { inferior a sua idade cronológica. } \\
\text { Os itens psicomotores de maior } \\
\text { atraso foram motricidade global, } \\
\text { equilíbrio e } \\
\text { linguagem/organização temporal. }\end{array}$ & $\begin{array}{c}\text { A criança com autismo do } \\
\text { estudo apresentou atraso no } \\
\text { desenvolvimento psicomotor, } \\
\text { possível de detectar por meio do } \\
\text { uso da EDM. }\end{array}$ \\
\hline
\end{tabular}




\begin{tabular}{|c|c|c|c|}
\hline 04 & $\begin{array}{c}\text { O método da Equoterapia, } \\
\text { utiliza-se de um cavalo } \\
\text { como instrumento } \\
\text { terapêutico, para um } \\
\text { desenvolvimento } \\
\text { biopsicossocial, com } \\
\text { melhoras nas funções } \\
\text { motoras e cognitivas. }\end{array}$ & $\begin{array}{c}\text { Questionário } \\
\text { semiestruturado. }\end{array}$ & $\begin{array}{l}\text { As contribuições trazidas pela } \\
\text { Equoterapia para as crianças } \\
\text { autistas são enormes, tanto físicas, } \\
\text { quanto mentais e sociais, pois, o } \\
\text { contato com o cavalo estimula os } \\
\text { movimentos do corpo, e também } \\
\text { faz com que o individuo crie } \\
\text { afeição pelo animal, e } \\
\text { posteriormente pelas pessoas, } \\
\text { ajudando em um desenvolvimento } \\
\text { biopsicossocial }\end{array}$ \\
\hline
\end{tabular}

\begin{tabular}{|c|c|c|c|c|}
\hline 05 & $\begin{array}{l}\text { Foi utilizado o teste ASQ3 } \\
\text { "Resolução de Problema", } \\
\text { com perguntas sobre } \\
\text { habilidades cognitivas. Os } \\
\text { participantes foram } 14 \\
\text { sujeitos, dos gêneros } \\
\text { feminino e masculino e } \\
\text { idade entre } 48 \text { e } 71 \text { meses, } \\
\text { com TEA. }\end{array}$ & $\begin{array}{l}\text { Teste Ages \& } \\
\text { Stages } \\
\text { Questionnaires } \\
(A S Q)\end{array}$ & $\begin{array}{l}\text { O ASQ foi capaz de identificar as } \\
\text { crianças com comprometimento } \\
\text { cognitivo e mostrou-se ser um } \\
\text { instrumento de fácil aplicação e } \\
\text { com baixo custo, atributos ideais } \\
\text { para uma ferramenta de avaliação } \\
\text { em cuidados de saúde primários. }\end{array}$ & $\begin{array}{l}\text { A ASK pode contribuir na } \\
\text { avaliação do autismo em } \\
\text { crianças. }\end{array}$ \\
\hline 06 & $\begin{array}{l}\text { O grupo } 1 \text { foi composto } \\
\text { por crianças com autismo } \\
\text { (AU), o grupo } 2 \text { por } \\
\text { crianças com síndrome de } \\
\text { Down (SD) e, finalmente, } \\
\text { o grupo } 3 \text { por crianças } \\
\text { com desenvolvimento } \\
\text { típico (DT). }\end{array}$ & $\begin{array}{l}\text { Protocolo de } \\
\text { Avaliação para } \\
\text { Crianças com } \\
\text { Suspeita de } \\
\text { Transtornos do } \\
\text { Espectro do } \\
\text { Autismo - PRO- } \\
\text { TEA }\end{array}$ & $\begin{array}{c}\text { Os itens do PRO-TEA foram } \\
\text { examinados por dois } \\
\text { observadores independentes, } \\
\text { cegos ao diagnóstico das crianças. } \\
\text { A fidedignidade entre os } \\
\text { avaliadores foi examinada por } \\
\text { meio do coeficiente Kappa. Os } \\
\text { itens referentes à atenção } \\
\text { compartilhada, brincadeira } \\
\text { simbólica e movimentos } \\
\text { repetitivos do corpo } \\
\text { discriminaram o grupo com TEA } \\
\text { dos controles, demonstrando o } \\
\text { potencial do instrumento. }\end{array}$ & $\begin{array}{l}\text { considerando-se que alguns dos } \\
\text { seus itens foram capazes de } \\
\text { discriminar crianças com } \\
\text { autismo dos controles, mesmo } \\
\text { em uma amostra reduzida. } \\
\text { Sendo de custo relativamente } \\
\text { baixo, se comparado a medidas } \\
\text { internacionais, este instrumento } \\
\text { poderá ser útil nos serviços } \\
\text { públicos de saúde. Por se tratar } \\
\text { de uma medida observacional e } \\
\text { direta, o instrumento } \\
\text { complementa outros como } \\
\text { questionários e entrevistas, } \\
\text { baseados em informações } \\
\text { obtidas com os pais/ cuidadores. }\end{array}$ \\
\hline 07 & Entrevista & $\begin{array}{c}\text { Questionário } \\
\text { semiestruturado }\end{array}$ & $\begin{array}{l}\text { A partir da análise dos dados } \\
\text { surgiram três categorias: 'a } \\
\text { descoberta do autismo'; } \\
\text { 'experiências dos familiares após } \\
\text { o diagnóstico de autismo' e } \\
\text { 'atendimento em saúde da criança } \\
\text { com autismo'. }\end{array}$ & $\begin{array}{l}\text { O autismo é um transtorno que } \\
\text { causa muitas adaptações e } \\
\text { mudanças na vida dos familiares } \\
\text { envolvidos, surgindo a } \\
\text { necessidade do apoio dos } \\
\text { profissionais de saúde no suporte } \\
\text { dos cuidados prestado a estas } \\
\text { crianças. }\end{array}$ \\
\hline 08 & Entrevista & $\begin{array}{c}\text { Questionário } \\
\text { semiestruturado }\end{array}$ & $\begin{array}{c}\text { Evidenciaram-se dois núcleos } \\
\text { temáticos: "Conhecimentos, } \\
\text { experiências e percepções sobre o } \\
\text { Transtorno do Espectro do } \\
\text { Autismo" e "O professor frente ao } \\
\text { aluno com Transtorno do } \\
\text { Espectro do Autismo e os } \\
\text { investimentos para a detecção e } \\
\text { inclusão". }\end{array}$ & $\begin{array}{l}\text { Concluiu-se que os professores } \\
\text { são capazes de identificar sinais } \\
\text { de autismo, contribuindo para o } \\
\text { diagnóstico precoce e que } \\
\text { experiências positivas } \\
\text { cooperaram para a acurácia na } \\
\text { detecção e para a inclusão } \\
\text { escolar. Ações intersetoriais e } \\
\text { interprofissionais necessitam ser } \\
\text { ampliadas a fim de oportunizar o } \\
\text { acolhimento e o cuidado } \\
\text { integral. }\end{array}$ \\
\hline
\end{tabular}

A interação com o cavalo contribui para desenvolver novas formas de comunicação, socialização, autoconfiança e autoestima, bem como, a satisfação de montar no cavalo, que os aceitam como são, fazem com que elas busquem demostrar seus sentimentos por meio de expressões, de sons ou de palavras, aumentando sua capacidade cognitiva. A ASK pode contribuir na avaliação do autismo em crianças. instrumento de fácil aplicação e para uma ferramenta de avaliação sujeitos, dos gêneros com TEA. or crianças com autismo Avaliação para Crianças com Suspeita de ranstornos do smo - PRO itens referentes à atenção compartilhada, brincadeira imbólica e movimentos scriminaram o grupo com TEA os controles, demonstrando o potencial do instrumento. questionários e entrevistas, obtidas com os pais/ cuidadores. $\mathrm{O}$ autismo é um transtorno que causa muitas adaptações e envolvidos, surgindo a necessidade do apoio do rofissionais de saúde no suporte crianças.

Concluiu-se que os professores são capazes de identificar sinais autismo, contribuindo para agnóstico precoce e que encias positivas operaram para a acurácia na detecção e para a inclusão escolar. Ações intersetoriais e interprofissionais necessitam ser acolhimento e o cuidado integral. 


\begin{tabular}{|c|c|c|c|c|}
\hline 09 & $\begin{array}{l}\text { Em meio ao impacto } \\
\text { familiar causado pelo } \\
\text { desfecho da investigação, } \\
\text { o infante passou a ser } \\
\text { acompanhado } \\
\text { continuamente por uma } \\
\text { equipe multidisciplinar } \\
\text { que contava com } \\
\text { psicólogo, fonoaudiólogo, } \\
\text { neuropediatra e terapeuta } \\
\text { ocupacional. }\end{array}$ & $\begin{array}{c}\text { Questionários } \\
\text { semiestruturados }\end{array}$ & $\begin{array}{l}\text { Revela-se a necessidade de maior } \\
\text { preparo dos profissionais da } \\
\text { educação no convívio com } \\
\text { criança autista ao evidenciar } \\
\text { desconhecimento e certo } \\
\text { preconceito destes no } \\
\text { relacionamento vivenciado a } \\
\text { princípio. }\end{array}$ & $\begin{array}{l}\text { A qualificação de professores e } \\
\text { demais profissionais, além de } \\
\text { infraestrutura adequada por meio } \\
\text { do fornecimento de insumos } \\
\text { necessários ao progresso da } \\
\text { criança com o transtorno } \\
\text { mostram-se essenciais ao } \\
\text { ensino-aprendizagem. }\end{array}$ \\
\hline 10 & Observação participante. & $\begin{array}{c}\text { Questionários } \\
\text { semiestruturados. }\end{array}$ & $\begin{array}{c}\text { Foi possível observar um } \\
\text { considerável desenvolvimento do } \\
\text { aluno autista. Por meio de práticas } \\
\text { pedagógicas diferenciadas, a } \\
\text { criança tem apresentado uma } \\
\text { maior socialização, mais } \\
\text { autonomia e progresso em sua } \\
\text { aprendizagem. O } \\
\text { acompanhamento diário ao aluno } \\
\text { revelou o quanto é necessário um } \\
\text { profissional apoio preparado, que } \\
\text { busque alternativas criativas, } \\
\text { lúdicas e adaptadas para facilitar a } \\
\text { aprendizagem das crianças com o } \\
\text { transtorno. }\end{array}$ & $\begin{array}{l}\text { Observou-se a importância de se } \\
\text { criar relações afetivamente } \\
\text { significativas e positivas com o } \\
\text { aluno autista, uma vez que o } \\
\text { profissional apoio é o seu } \\
\text { mediador na escola regular de } \\
\text { ensino. Esse educador é } \\
\text { responsável por transmitir o } \\
\text { conhecimento de forma que o } \\
\text { aluno entenda, favorecendo a } \\
\text { sua confiança, autonomia e } \\
\text { interação social que são } \\
\text { primordiais para o seu } \\
\text { desenvolvimento geral }\end{array}$ \\
\hline
\end{tabular}

Fonte: Autores (2021).

\section{Discussão}

Ramos et al (2019) realizou um estudo com 42 crianças com desenvolvimento típico, na faixa etária de 4-5 anos, de dois Centros de Referência em Educação Infantil (CREI) da Rede Municipal de Ensino da cidade de João Pessoa, no estado da Paraíba, Brasil, sendo 21 crianças de cada CREI. O estudo concluiu que se torna muito relevante à inclusão escolar das crianças com TEA desde a Educação Infantil, pois isso pode possibilitar uma ampliação das suas experiências sociais e oportunizar aos seus pares a conscientização da diversidade que é própria do ser humano.

Os autores ressaltam ser necessária uma discussão junto aos educadores e pais as políticas de inclusão, uma vez que as atitudes e discursos daqueles influenciarão na maneira como as crianças com desenvolvimento típico vão perceber e interagir com seus colegas com TEA (Ramos et al., 2019).

Anjos et al (2017) desenvolveu pesquisa com 30 crianças na faixa de idade entre 2 e 11 anos, de ambos os gêneros, com diagnóstico de Transtorno do Espectro do Autismo leve. Os resultados do estudo demonstraram que perfil psicomotor médio encontrado nas crianças com TEA que foram avaliadas demonstrou que as mesmas estão em um nível inferior em relação ao desenvolvimento dos aspectos psicomotores esperados para a sua idade cronológica. Identificou-se também a presença de déficits em todos os elementos psicomotores, sendo os mais comprometidos o esquema corporal e a organização temporal. E os menos comprometidos Motricidade Global, Equilíbrio e Organização Espacial.

Já no estudo realizado por Santos e Melo (2018) realizado com uma criança com TEA onde a mesma foi avaliada por uma bateria de Testes de Avaliação Motora da EDM (Escala de Desenvolvimento Motor) nos aspectos de motricidade fina, motricidade global, equilíbrio, esquema corporal, organização espacial, organização temporal e lateralidade.

Os resultados do estudo supracitado apresentaram que a criança avaliada pela EDM apresenta atraso no Desenvolvimento Neuropsicomotor (DNPM), sendo identificado um atraso de 02 anos na criança com TEA avaliada, 
principalmente no que se relaciona à motricidade global, equilíbrio e linguagem/organização temporal, alterações essas que ocorrem de forma não linear e podem repercutir no processo de aprendizagem (Santos; Melo, 2018).

No estudo realizado por Cruz e Pottker (2017) que teve como objetivo investigar as contribuições da Equoterapia para o desenvolvimento psicomotor da criança com TEA. Os resultados do estudo apontaram que as contribuições trazidas pela Equoterapia para as crianças com TEA são enormes, tanto físicas, quanto mentais e sociais, pois, o contato com o cavalo estimula os movimentos do corpo, e também faz com que a criança crie afeição pelo animal, e consequentemente pelas pessoas, ajudando assim em um desenvolvimento biopsicossocial.

Os autores ainda apontam que é papel do psicólogo na Equoterapia está no acompanhamento dos participantes durante as atividades, buscando assim trabalhar os conflitos e traumas existentes, o que visa recuperar a autoconfiança da criança (Cruz; Pottker, 2017).

No estudo de Tomazoli et al (2017), realizado com o objetivo de verificar se o Ages \& Stages Questionnaires (ASQ) é eficaz para rastrear alterações cognitivas em crianças com TEA, e se existem diferenças entre as respostas dadas pelos cuidadores e terapeutas da criança. Apontaram que o Ages \& Stages Questionnaires mostrou-se um instrumento com as características supracitadas, identificando adequadamente que os indivíduos com TEA têm um desempenho cognitivo abaixo do esperado no que se relaciona a idade.

Já no estudo de Couto et al (2019) realizado com professores de Centros Municipais da Educação Infantil (CMEIs) de Foz do Iguaçu, Paraná, Brasil. Os resultados do estudo demonstraram que a percepção do TEA pelas professoras é fruto de uma teia intrincada de informações adquiridas, sentimentos, vivências, ideias do senso comum, aspirações e valores pessoais. Notou-se que as opiniões sobre o autismo não se resumiram apenas a informações objetivas; vieram permeadas de elementos do cotidiano em sala de aula e das experiências pessoais, boas ou não, no contato com alunos com TEA.

O estudo de Melo et al (2019), demonstraram que embora não haja pela medicina uma etiologia definida para o TEA, atualmente se conta com diversas terapias alternativas voltadas ao controle e melhoria da qualidade de vida da criança com o transtorno. Nota-se também diversos avanços legislativos e tecnológicos que incluem a criança com a patologia na sociedade e principalmente no ambiente escolar, proporcionando assim seu pleno desenvolvimento cognitivo e social.

No estudo de Hofzmann et al (2019) realizado com familiares de crianças com diagnóstico de TEA da Associação de Pais e Amigos dos Excepcionais (APAE), de um município de Santa Catarina, os autores perceberam o quão impactante é o diagnóstico de TEA para os familiares. A falta de conhecimento sobre o assunto impera sobre a maioria, trazendo insegurança e sentimentos diversos. Fica evidente que o diagnóstico precoce se torna a chave para o bom prognóstico e desenvolvimento da criança com TEA, os autores mencionam que quanto mais jovem maior as chances de melhora do quadro devido à plasticidade cerebral.

Teixeira e Ganda (2019) realizaram um estudo apresentar as atividades realizadas pela profissional-apoio e o impacto no desenvolvimento da criança autista. Os resultados apontaram que por meio de diversas metodologias pedagógicas diferenciadas, o participante do estudo apresentou maior socialização, mais autonomia e progresso em sua aprendizagem. Os autores ressaltam que acompanhamento diário ao aluno com TEA revela o quanto é necessário um profissional de apoio que esteja preparado, que busque alternativas criativas, lúdicas e adaptadas para facilitar a aprendizagem das crianças com TEA.

\section{Conclusão}

Diante da literatura discutida foi possível refletir sobre o impacto do TEA no desenvolvimento infantil, identificar quais aspectos do desenvolvimento infantil são mais afetados pelo autismo e analisar o processo de aprendizagem da criança autista. 
Conclui-se com esta pesquisa que os aspectos mais afetados no desenvolvimento infantil afetados pelo TEA mencionados na literatura são o atraso no Desenvolvimento Neuropsicomotor, principalmente no que se relaciona à motricidade global, equilíbrio e linguagem/organização temporal, alterações essas que ocorrem de forma não linear e podem repercutir no processo de aprendizagem.

Sobre o processo de aprendizagem da criança autista a literatura aponta esse processo deve ser realizado através de metodologias pedagógicas diferenciadas para que essa criança crie autonomia e progresso em sua aprendizagem.

A literatura também ressalta que acompanhamento diário e especializado da criança com TEA revela o quanto faz-se necessário um profissional de apoio que esteja preparado, que busque alternativas criativas e lúdicas que adaptadas e individualizada, facilitando assim a aprendizagem de crianças com TEA. Recomenda-se a elaboração do novos estudos para que se tenha conclusões mais significativas sobre a temática em pauta.

\section{Referências}

Anjos, C. C., et al (2017). Perfil Psicomotor de Crianças com Transtorno do Espectro Autista em Maceió/AL. Revista Portal: Saúde e Sociedade, 2(2), 395410 .

Couto, C. C., et al (2019). Experiências de professores com o autismo: impacto no diagnóstico precoce e na inclusão escolar. Rev. Eletr. Enferm, 21:55954, 17 .

Cruz, B. D. Q., \& Pottker, C. A. (2017). As contribuições da equoterapia para o desenvolvimento psicomotor da criança com transtorno de espectro autista. Revista UNINGÁ Review, 32(1), 147-158.

Cunha, E. (2014). Autismo e Inclusão - Psicopedagogia e práticas educativas na escola e na família. (5a ed.), Wak editora.

Cunha, E. (2016). Práticas pedagógicas para inclusão e diversidade. (6a ed.), Wak editora.

Hofzman, R. R., et al (2019). Experiência dos familiares no convívio de crianças com transtorno do espectro autista (TEA). Enferm. Foco, 10 (2): 64-69.

Marconi, M. A., \&Lakatos, E (2014). Mª Fundamentos de Metodologia Científica. (6a ed.), Atlas.

Marques, D. F., \& Bosa, C. A. (2015). Protocolo de Avaliação de Crianças com Autismo: Evidências de Validade de Critério. Psicologia: Teoria e Pesquisa, $31(1), 43-51$.

Mendes, K. D. S., Silveira, R. C. C. P., \& Galvão, C. M (2008). Revisão integrativa: método de pesquisa para a incorporação de evidências na saúde e na enfermagem. Texto Contexto Enferm., 17(4), 758-764.

Melo, M. M., et al (2019). Atendimento multidisciplinar para a educação especial e inclusiva de uma criança com transtorno do espectro autista: um estudo de caso. REAS/EJCH, 25, 1-6.

Ramos, C. S. A., Lemos, E. L. M. D., \& Salomão, N. M. R. (2019). Vivências Escolares e Transtorno do Espectro Autista: o que Dizem as Crianças? Rev. Bras. Ed. Esp., Bauru, 25(3), 453-468.

Santos, E. D. F., \& Melo, T. R. (2018). Caracterização psicomotora de criança autista pela escala de desenvolvimento motor. Divers@, Matinhos, 11(1), 5058.

Sasson, N., Nowlin, R. P. (2012). A. Social cognition, social skill and the broad autism phenotype. Autism. The International Journal of Research and Practice, v. 17, n. 6, p. 655-667, Sept.

Teixeira, M. C. S., \& Ganda, D. R. (2019). Inclusão E Autismo: relato de caso sobre o trabalho com uma criança na educação infantil. Rev. Psicol Saúde e Debate: $5(2): 125-135$.

Tomazoli, L. S., Santos, T. H. F., Amato, C. A. H., Fernandes, F. D. M., \& Molini-Avejonas, D. R. (2017). Rastreio de alterações cognitivas em crianças com TEA: estudo piloto. Psicologia: teoria e prática, 19(3): 23-32.

Willians, C., \& Wright, B. (2008). Convivendo com Autismo e Síndrome de Asperger. M. Books. 